\title{
Audit Quality and Corporate Innovation
}

\author{
Jian-hua Kong \\ Chengdu Textile College, Chengdu 611731
}

Keywords: Audit Quality, Corporate Governance, Agency Cost, Analyst Coverage, Media Coverage.

\begin{abstract}
In the background of implementation the strategy of innovation-driven development, this paper investigates the impact of audit quality on corporate innovation. Using applications of invention patents as a proxy of corporate innovation, we find that audit quality (measured by international Big Four and eight largest audit firms, respectively) significantly enhance the corporate innovation; the positive relation between audit quality and corporate innovation will be more pronounced in firms facing higher agency cost or financing constrains; and this effect will be mitigated by analyst coverage and media supervision.
\end{abstract}

\section{Introduction}

Enterprise innovation is not only the key to establish and maintain the competitive advantage of an enterprise itself, but also an important support to promote a country's comprehensive national strength and promote the progress of social productive forces. Therefore, it has attracted the attention of both the theoretical and practical fields. In particular, it is of great theoretical and practical significance to discuss how to promote enterprise innovation in the context of China's clearly stated implementation of the innovation driven development strategy to adapt to the new normal environment of China's economic development.

The contribution of this paper is mainly reflected in: (1) found that external audit quality significantly promote the business innovation activities, enrich the enterprise innovation and the factors affecting the field; (2) for the first time will be linked to the strategic investment behavior of the enterprise audit quality and innovation important, enriches the study on the audit quality of economic consequences; (3) discussed the relationship of agency problems, financing constraints and other corporate governance mechanisms on audit quality and innovation of the two, reveals the auditing quality of enterprise innovation mechanism.

\section{Theoretical analysis and research hypothesis}

This paper argues that the improvement of external audit quality contributes to enterprise innovation, for the following reasons.

First of all, the improvement of external audit quality will help to alleviate the conflict between shareholders and managers and enhance the enterprise's willingness to innovate. Secondly, the improvement of external audit quality will help to ease the financing constraints and enhance the innovative ability of enterprises. Therefore, the research hypothesis of this paper is put forward1[1].

$\mathrm{H} 1$ : the higher the audit quality, the higher the level of innovation of the enterprise, the two are positively related.

In hypothesis 1, this paper points out that audit quality may contribute to enterprise innovation by alleviating agency problems. If this logic is established, it can be expected that when the cost of enterprise agents is higher, the positive correlation between the two will be more significant. Because if the enterprise does not have agency problems, interests and the interests of shareholders' exactly the same, even if does not need external audit, managers will also carry out innovation activities based on the goal of maximizing shareholder value, enterprise innovation is not affected by the audit quality. On the contrary, with the increase of agency cost, the deviation of the objective 
function between managers and shareholders will continue to increase, if the lack of necessary supervision, managers will be difficult to carry out private shareholders based on interests, the high cost of innovation. At this point, high quality audit services have more room to play, and can better coordinate the conflicts of interests between managers and shareholders, and enhance the willingness of managers to implement innovative activities. It is assumed that 2 .

$\mathrm{H} 2$ : with the increase of agency cost, the positive relationship between audit quality and enterprise innovation is enhanced.

In hypothesis 1 , the paper also points out that audit quality may promote enterprise innovation by alleviating financing constraints. If this logic is established, it can be expected that when the degree of enterprise financing constraints is higher, the positive correlation between the two will be more significant. Because if the enterprise does not have financing constraints, it will have sufficient resources to implement innovative activities, without relying on the external audit certification function, reducing financing costs. On the contrary, when enterprises are facing financing constraints when high quality audit services can better play the function of supervision, to reassure investors in advance, during and after the perception of uncertainty, so as to enable the enterprise to lower cost into more funds to support innovation activities. It is assumed that 3.

H3: with the increase of financing constraints, the positive relationship between audit quality and enterprise innovation is enhanced.

In addition to auditing, analysts and the media are also considered as important external corporate governance mechanisms (Li Chuntao et al., 2014; Zhou Kaiguo et al., 2016). Then, does audit quality and other external supervision mechanisms play an alternative or complementary role in enterprise innovation? Yang Deming et al. (2009) found that the level of internal control and audit quality had an alternative role in reducing agency problems. The internal and external supervision mechanisms have similar functions in nature, so we propose hypothesis 4.

H4: with the improvement of other external corporate governance mechanisms, the positive relationship between audit quality and enterprise innovation is weakened.

\section{Research design}

This article selects 2003-2013 Shanghai and Shenzhen two listed A shares of listed companies as the research object, the number of patent applications and types are derived from the State Intellectual Property Office "China patent full-text database"; comprehensive evaluation of firm ranking data from the Chinese CPA Association website, analysts and media reports and other required data from the CSMAR database. Considering that the earliest year of analyst forecast data in CSMAR database is 2003, the research period started in 2003[2].

In the concrete sample selection process, this article has carried on the following processing: (1) excluding the financial industry sample; (2) excluding the incomplete sample of the data needed in the research. Based on the above criteria, 17555 firm annual observations are finally obtained. At the same time, Winsorize processing is performed at the $1 \%$ and $99 \%$ levels of the continuous variable in the model to reduce the interference of the data outliers on the results.

The model is tested by hypothesis (1), (2), (3) and (4) hypothesis 1 to hypothesis 4 . Considering the dependent variable, the number of patent applications can not be negative, and it is a trailing variable with a lower limit of 0 . Therefore, the Tobit model is used to estimate.

$$
\begin{aligned}
& \operatorname{Ln}(1+P A T)_{i, t+1}= \alpha+\beta_{1} \times A Q_{i, t}+\gamma \times{\text { Control } \text { Variables }_{i, t}+\varepsilon_{i, t}}= \\
& \operatorname{Ln}(1+P A T)_{i, t+1}= \alpha+\beta_{1} \times A Q_{i, t}+\beta_{2} \times A Q_{i, t} \times A C_{i, t}+\beta_{3} \times A C_{i, t}+ \\
& \gamma \times \text { Control Variables }_{i, t}+\varepsilon_{i, t} \\
& \operatorname{Ln}(1+P A T)_{i, t+1}= \alpha+\beta_{1} \times A Q_{i, t}+\beta_{2} \times A Q_{i, t} \times F C_{i, t}+\beta_{3} \times F C_{i, t}+ \\
& \gamma \times \text { Control Variables } \\
& i, t
\end{aligned}
$$




$$
\begin{aligned}
\operatorname{Ln}(1+P A T)_{i, t+1}= & \alpha+\beta_{1} \times A Q_{i, t}+\beta_{2} \times A Q_{i, t} \times E C G_{i, t}+\beta_{3} \times E C G_{i, t}+ \\
& \gamma \times \text { Control Variables }_{i, t}+\varepsilon_{i, t}
\end{aligned}
$$

Referring to Jiang Xuanyu (2016) research, this paper uses the number of patent applications for PAT to measure enterprise innovation and processes it by logarithm.

Referring to the existing research (Gul, et al., 2010, Chen, etc., 2011), this paper evaluates the audit quality from the perspective of firm size AQ. The two methods are as follows: (1) whether to hire four international accounting firm BIG4, if the company hired four international accounting firm joint venture of audit, BIG4 value of 1 , or 0 ; (2) whether to hire a major accounting firm TOP8, every year, are sorted according to the comprehensive evaluation of accounting firms firm China CPA Association website 100 information, if the company hired the firm ranked among the top ranking in the top eight, TOP8 value is 1 , otherwise 0 .

Referring to Li Yunhe (2014) approach, MFEE is used to measure the agency cost AC between shareholders and managers with management expense ratio (management fee / main business income).

The reference solution Wiseman and Fang Hongxing (2011) approach to enterprise scale SIZE measure the degree of financing constraints of enterprises. SIZE is the natural logarithm of the book value of the total assets of the company. Theoretically, compared with large enterprises, the financing constraints of small enterprises are higher. Therefore, the smaller the SIZE, the more serious the financing constraints the enterprises are subjected to.

This article mainly from the degree of analyst concern, AF and media attention MEDIAN two dimensions to measure the strength of other external governance mechanism. Among them, AF=Ln (1+ analysts track the number of years), MEDIAN=Ln (1+ years of news media reports on the number of companies). The greater the value of AF and MEDIAN, the more perfect the company's external governance[3].

According to the literature (Jiang Xuanyu, 2016), the main control variables are as follows: SIZE, the natural logarithm of total assets; Tobin, Q; the ratio of OCTA company operating activities net cash flow to total assets; the ratio of PPETA, net value of fixed assets to total assets of the company; financial leverage of the company's total assets return rate of LEV; ROA; natural logarithm of AGE year; the proportion of the first shareholder and FIRST square and the proportion of managerial ownership; MHOLD; stock turnover rate of TURNOVER years; the enterprise property rights SOE; in addition, also joined the annual industry dummy variables and dummy variables to control year and industry fixed effects[4].

\section{The main empirical results}

It can be found, whether using BIG4 or TOP8 to measure the audit quality of AQ, the regression coefficient is significantly positive, which is from the overall perspective, the higher the quality of the audit, the innovation capability is strong, consistent with the theoretical analysis of $\mathrm{H} 1$.

As the first agency problem intensifies, audit quality is a positive role in promoting the innovation of enterprises is more significant, are consistent with the theoretical analysis of H2; at the same time, the coefficient of MFEE is significantly negative, that the agency problems more serious, its innovation level is low, consistent with the existing literature. From the two row shows that the regression coefficient BIG4*SIZE and TOP8*SIZE are significantly negative, whereas SIZE negatively reflect the degree of financing constraints, the results show that the degree of financing constraints intensifies, audit quality is a positive role in promoting the innovation of enterprises is more significant, consistent with the theory of H3 analysis; at the same time, SIZE the coefficient is significantly positive, that the lower the level of financing constraints, enterprise innovation level is higher, consistent with the existing literature[5].

Although the explanatory variables in this paper are lag first order, to some extent, they help to overcome the endogenous relations among variables, but endogeneity problems still exist. For example, the four big (eight) CPA firms are more willing to undertake innovative business audits. In order to further alleviate the interference of endogenous problems on the conclusions of this study, 
the Heckman two stage model is used for regression. The first stage of the Probit model, the reference beam, and the (2015) setting, is as follows:

$$
\begin{aligned}
& B I G 4(T O P 8)_{i, t}=\alpha+\beta_{1} S_{Z Z E_{i, t}}+\beta_{2} L E V_{i, t}+\beta_{3} R O A_{i, t}+\beta_{4} S O E_{i, t}+ \\
& \beta_{5} G R O W T H_{i, t}+\beta_{6} C_{U R R}+\beta_{7} I_{i N V R}+\beta_{6} R_{i, t} C R_{i, t} \\
& + \text { Year }+ \text { Industry }+\varepsilon_{i, t}
\end{aligned}
$$

Among them, GROWTH is the sales revenue growth rate; CURR as the mobile company asset to total asset ratio; INVR for the company's stock value and total asset ratio; RECR for the company's accounts receivable to total asset ratio; other variables are consistent with the above definition, no longer. The results of the first stage are shown in the first two columns of table 5, which shows that the clients of BIG4 and TOP8 accountants have the characteristics of larger scale, lower debt ratio and higher proportion of receivables.

Based on the above first stage regression, the estimated inverse Mills coefficient IMR is substituted into the model (1), and the second stage regression test is carried out. The results are shown in the latter two columns of table 1. It can be found that, after controlling the inverse Mills coefficient IMR, the regression coefficients of BIG4 and TOP8 are 0.206 and 0.070, respectively, at the confidence level of $1 \%$ and $10 \%$, respectively. This shows that after controlling the endogeneity of the choice of accounting firms, the conclusions of this study are still valid.

First of all, this article uses innovation patents and utility model patents as the sum of quantities and PAT1's natural logarithm ln $(\mathrm{PAT} 1+1)$ to measure enterprise innovation. Secondly, from innovation investment, that is, $\mathrm{R} \& \mathrm{D}$ cost to total assets ratio, RDTA and R \& D expense ratio of sales revenue, RDSA measures enterprise innovation, and then returns to model (1). Because the WIND database provides only data for R \& D in 2006 and beyond, the sample size is reduced to 15176. As can be seen from the table, the main conclusions remain unchanged.

\section{Conclusions and implications}

Based on the sample of Shanghai and Shenzhen A-share listed companies in the 2003-2013 years, this paper empirically examines the relationship between audit quality and enterprise innovation, and the effects of agency costs, financing constraints, and other external governance mechanisms on the relationship between the two firms A. The study found that: (1) is positively related to audit quality and enterprise innovation, that audit quality by improving the external supervision level, help to promote enterprise innovation; (2) the positive relationship between audit quality and enterprise innovation is enhanced with the agency problems and financing constraints intensified, that improve the level of corporate governance and reduce corporate financing the constraint is an important way to promote the innovation of enterprises; (3) with analysts and media attention to improve the level of supervision, weaken the positive relationship between the two, that the audit quality and other external corporate governance mechanism in enterprise innovation have a certain substitution effect.

The research conclusion of this paper has certain theoretical and practical significance. In theory, the research of this paper enriches the relevant literatures about the factors affecting enterprise innovation and audit quality and economic consequences. In practice, the conclusions of this study are as follows. (1) for enterprises, should better recognize the significance of external audit, make full use of the high quality of the external audit governance function, effectively alleviate the agency problem and its financial constraint level, and to promote enterprise innovation, in the increasingly fierce competition to establish and maintain market advantage. (2) for the auditor, should be more deeply aware of their work, efforts should be made to improve the professional quality, enhance the independence, by providing high quality audit services for customers, promote the enterprises to carry out innovation activities, to provide for the national audit industry since the implementation of innovative development strategy support. 


\section{References}

[1] Bertrand, M., and Mullainathan, S.. Enjoying the Quiet Life? Corporate Governance and Managerial Preferences. Journal of Political Economy, 2003, 111(5): 1043-1075.

[2] Chen, H.W., Chen, J.Z., Lobo, G. J., and Wang, Y.Y.. Effects of Audit Quality on Earnings Management and Cost of Equity Capital: Evidence from China. Contemporary of Accounting Research, 2011, 28(3): 892-925.

[3] Gul, F. A., Kim, J.-B., and Qiu, A.. Ownership Concentration, Foreign Shareholding, Audit Quality, and Stock Price Synchronicity: Evidence from China. Journal of Financial Economics, 2010, 95(3): 425-442.

[4] Jensen, M.C., and Meckling, W.H... Theory of the Firm: Managerial Behavior, Agency Costs, and Ownership Structure. Journal of Financial Economics, 1976, 3(4): 305-360.

[5] Wright, P., Ferris, S. P., Sarin, A., and Awasthi, V.. Impact of Corporate Insider, Blockholder, and Institutional Equity Ownership on Firm Risk Taking. The Academy of Management Journal, 1996, 39(2): 441-463. 